\title{
DEVELOPMENT, CONSTRUCTION AND EXPERIMENTAL TESTING OF THE SYSTEM FOR MONITORING THE TIP OVER STABILITY OF A SINGLE BUCKET EXCAVATOR
}

\begin{abstract}
A. Kosiara*
Abstract: The article points out that the operator of a single bucket excavator should have the access to the information about current tip over stability margin of the operated machine to ensure his efficient and safe work. An algorithm for calculating the index characterizing the current stability margin of the excavator has been proposed. The prototype of the tip over stability monitoring system built based on this algorithm is also described.
\end{abstract}

Keywords: excavators, tip over stability, monitoring system, mechatronics

\section{Introduction}

Tip over stability in addition to directional stability while driving (Dudziński et al., 2012a, Dudziński et al., 2012b) is one of the most important co-determinants of the safe operation of mobile earthmoving machines. The problem of the tip over stability with regard to wheeled vehicles (Dudziński et al., 2015, Dudziński et al., 2017) as well as with regard to tracked vehicles (Kosiara et al., 2017) has been the subject of many scientific works. This publication focuses on the tip over stability of excavators. In order to avoid the loss of tip over stability of the excavator, the operator should follow a number of guidelines resulting from the manufacturer's standard recommendations and / or instructions. According to the current practice, the excavator manufacturer specifies the so-called tip over loads for various positions of working gear. The user in turn, taking these loads into account, selects for a working tool, e.g. a bucket. It is required that the bucket volume be such that its weight with the load does not exceed $75 \%$ of the tip over load associated with the attachment used. The presented procedure is in accordance with the recommendations of ISO 10567. A 25\% margin is assumed due to the possibility of additional tip over moments occurring during the lifetime of the excavator as a result of dynamic forces. The literature (Dudczak, 2000) shows that very high values of dynamic forces may appear, for example, when slowing down the movement of lowering the boom with the straightened arm.

The tip over load for a given working attachment position according to ISO 10567 is considered to be the load of the manipulator, at which the machine achieves an unstable equilibrium. It is a state in which, for the considered tip over edge, the resultant tip over moment acting on the machine is equal to the moment counteracting the tip over of the machine.

Experience shows that a 25\% safety factor adopted in accordance with ISO 10567 effectively protects the excavator against falling over during operation, provided that it works on a stable, flat surface. If the excavator is placed on a slope or on unstable ground, compliance with the standard recommendations does not guarantee safety. The operator in such conditions must rely heavily on his experience, intuition and additional knowledge. In such a situation, there is an increased risk that a person operating the machine may, as a result of temporary distraction or due to poor assessment of the excavator's working conditions, make wrong decisions. They, in turn, may result in the excavator's loss of tip over stability.

Assoc. Prof. Andrzej Kosiara, PhD.: The Department of Off-Road Machine and Vehicle Engineering, Wrocław University of Science and Technology; Łukasiewicza 7/9; 50-371, Wrocław; PL, andrzej.kosiara@pwr.edu.pl 
For the aforementioned reason, it seems that the operator should have at his disposal a system that would monitor the excavator's tip over stability on an ongoing basis. This could help him quickly make the right decision in many situations. As a result, it would have a positive impact on work safety and on the excavator's operational efficiency. The following article describes a prototype of this type of system built by the author for use on an excavator.

\section{Description of the operation of the developed monitoring system}

It was assumed that the excavator consists of 7 units: chassis (1), body (2), swing bracket (3), boom (4), arm (5), quick couplers with load transducer (6) and bucket with load (7). In order to monitor the stability of the excavator, the system defines the so-called stability margin factor. It has been defined as the distance of the projection of the center of gravity of the entire machine from the nearest edge of the tipping over (Kosiara, 2017b). The center of gravity is projected onto the ground plane and the direction of projection is determined by the gravitational acceleration vector. The stability margin factor determined in this way before presenting it to the operator is normalized and expressed as a percentage. This factor is presented to the operator in numerical form and graphically by means of a pictogram. A fall in the stability factor below $0 \%$ means that the excavator has started to tip over.

The calculations made by the developed device start from the designation for the bucket of the excavator together with the load: weight $\mathrm{Q}_{7}$ and the coordinate position of the center of gravity $x_{C G 7}^{C S 7}$ in the local bucket coordinate system CS7. The calculations are based on the load components acting on the quick coupler measured by the sensor embedded in the coupler. These calculations are carried out in accordance with the following relationships:

$$
\begin{gathered}
Q_{7}=\sqrt{\left(F_{x}^{C S 7}\right)^{2}+\left(F_{y}^{C S 7}\right)^{2}} \\
x_{C G 7}^{C S 7}=\frac{M_{y}^{C S 7}}{Q_{7}}
\end{gathered}
$$

The local coordinate system of the bucket 7 , unlike other local coordinate systems of the excavator units, can change its orientation with respect to the bucket itself. It is characterized by the fact that its $\mathrm{z}$ axis is always directed vertically upwards and its axes $\mathrm{x}$ and $\mathrm{y}$ run horizontally. Loads are measured in the CS6 quick coupler coordinate system and later converted to the CS7 bucket coordinate system.

The coordinates of position of the centers of gravity of the excavator units numbered from 1 to 6 are entered by the operator into the memory of the microcontroller before the system is started. They are expressed in local coordinate systems that change their position relative to the chassis coordinate system. The system continuously, in real time, recalculates them to the CS1 chassis coordinate system. The axes $\mathrm{x}$ and y of the CS1 system are placed on the ground plane on which the excavator stands. Conversions take place in accordance with the following relationships:

$$
\begin{gathered}
P_{C G 1}^{C S 1}=T^{C S 2 \rightarrow C S 1} \cdot T^{C S 3 \rightarrow C S 2} \cdot T^{C S 4 \rightarrow C S 3} \cdot T^{C S 5 \rightarrow C S 4} \cdot T^{C S 6 \rightarrow C S 5} \cdot T^{C S 7 \rightarrow C S 6} \cdot P_{C G 7}^{C S 7} \\
P_{C G 6}^{C S 1}=T^{C S 2 \rightarrow C S 1} \cdot T^{C S 3 \rightarrow C S 2} \cdot T^{C S 4 \rightarrow C S 3} \cdot T^{C S 5 \rightarrow C S 4} \cdot T^{C S 6 \rightarrow C S 5} \cdot P_{C G 6}^{C S 6} \\
P_{C G 5}^{C S 1}=T^{C S 2 \rightarrow C S 1} \cdot T^{C S 3 \rightarrow C S 2} \cdot T^{C S 4 \rightarrow C S 3} \cdot T^{C S 5 \rightarrow C S 4} \cdot P_{C G 5}^{C S 5} \\
P_{C G 4}^{C S 1}=T^{C S 2 \rightarrow C S 1} \cdot T^{C S 3 \rightarrow C S 2} \cdot T^{C S 4 \rightarrow C S 3} \cdot P_{C G 4}^{C S 4} \\
P_{C G 3}^{C S 1}=T^{C S 2 \rightarrow C S 1} \cdot T^{C S 3 \rightarrow C S 2} \cdot P_{C G 3}^{C S 3} \\
P_{C G 2}^{C S 1}=T^{C S 2 \rightarrow C S 1} \cdot P_{C G 2}^{C S 2}
\end{gathered}
$$

where: $T^{C S i \rightarrow C S j}$ - the matrix of position transformation from the coordinate system $i$ to the coordinate system $j, P_{C G k}^{C S m}$ - the position vector of the center of gravity of the unit $k$ in the local coordinate system of the unit $m$. Before the coordinates are converted according to the relations $(3 \div 8)$ the readings of the seven sensors are taken. The values enable the specification of mutual orientation of all excavator units and the angle of inclination of the ground. After determining the positions of the centers of gravity of the excavator's units in the chassis coordinate system, the developed system proceeds to find the position of the center of gravity of the entire excavator in the CS1 coordinate system using the following relationship: 


$$
P_{C G}^{C S 1}=\left[\begin{array}{c}
x_{C G}^{C S 1} \\
y_{C G}^{C S 1} \\
z_{C G}^{C S 1}
\end{array}\right]=\left[\begin{array}{c}
\frac{\sum_{i=1}^{i=7}\left(m_{i} \cdot x_{C G i}^{C S 1}\right)}{\sum_{i=1}^{i=7} m_{i}} \\
\frac{\sum_{i=1}^{i=7}\left(m_{i} \cdot y_{C G i}^{C S 1}\right)}{\sum_{i=1}^{i=7} m_{i}} \\
\frac{\sum_{i=1}^{i=7}\left(m_{i} \cdot z_{C G i}^{C S 1}\right)}{\sum_{i=1}^{i=7} m_{i}}
\end{array}\right]
$$

The next stage of calculations performed by the system is to find the coordinates of the projection of the center of gravity of the excavator on the ground plane using the following relationship:

$$
P_{C G \text {-projection }}^{C S 1}=\left[\begin{array}{l}
x_{C G-\text { projection }}^{C S 1} \\
y_{C G-\text { projection }}^{C S 1} \\
z_{C G-\text { projection }}^{C S 1}
\end{array}\right]=\left[\begin{array}{c}
x_{C G}^{C S 1}+z_{C G}^{C S 1} \cdot \frac{\sin (\alpha) \cdot \cos (\varphi)}{\cos (\alpha)} \\
y_{C G}^{C S 1}+z_{C G}^{C S 1} \cdot \frac{\sin (\alpha) \cdot \sin (\varphi)}{\cos (\alpha)} \\
0
\end{array}\right]
$$

In equation (10) symbol $\alpha$ represents the angle of inclination of the ground plane on which the excavator stands whereas the symbol $\varphi$ is the excavator orientation angle on the ground plane. The last stage of calculations involves finding the value of stability margin factor SI [\%]. This stage of calculations is based on relationships (11), (12) and (13).

$$
\begin{array}{r}
S I_{x}=\min \left(\frac{B}{2}-x_{C G-\text { projection }}^{C S 1} ; \frac{B}{2}+x_{C G-\text { projection }}^{C S 1}\right) \\
S I_{y}=\min \left(\frac{L}{2}-y_{C G-\text { projection }}^{C S 1} \frac{L}{2}+y_{C G-\text { projection }}^{C S 1}\right) \\
S I[\%]=\min \left(\frac{S I_{x}}{\frac{B}{2}} \cdot 100 \% ; \frac{S I_{y}}{\frac{L}{2}} \cdot 100 \% ;\right)
\end{array}
$$

The relationships $(11 \div 13)$ use the following symbols: $B$ - spacing of the lateral edges of the excavator tip over, $L$ - distance between the front and the rear excavator tip over edge. After determining the value of the stability margin factor, it is presented in numerical and graphical form on the screen to the operator.

\section{Construction of the prototype system for monitoring the excavator's tip over stability}

The prototype device was built on the basis of the described in point 2 concept of the monitoring system of tip over stability of excavator. It was built so as to: a) verify the formulated computational algorithm, b) check whether the performance of the intended controller and monitor are sufficient, c) check the usable properties of the designed device and its suitability for the person operating the excavator. The prototype of the device was mounted on the laboratory stand shown in Fig. 1 and subjected to experimental tests. Selected screenshots of the system during its experimental testing are shown in Fig. 2.

\section{Summary}

The article presents a calculation algorithm developed for the tip over stability monitoring system of an excavator. Based on this algorithm, the author built a prototype device, which was then mounted on the testing stand and subjected to preliminary tests. The results of the experiments confirmed the correctness of the developed software code. The resolution of the screen and the computing power of the microcontroller proved to be sufficient. The form of information presentation on the screen was clear and intuitive for the operator. Based on the research conducted so far, it seems that the developed system can be very helpful for a person forced to operate a standing excavator or moving on an inclined ground. 


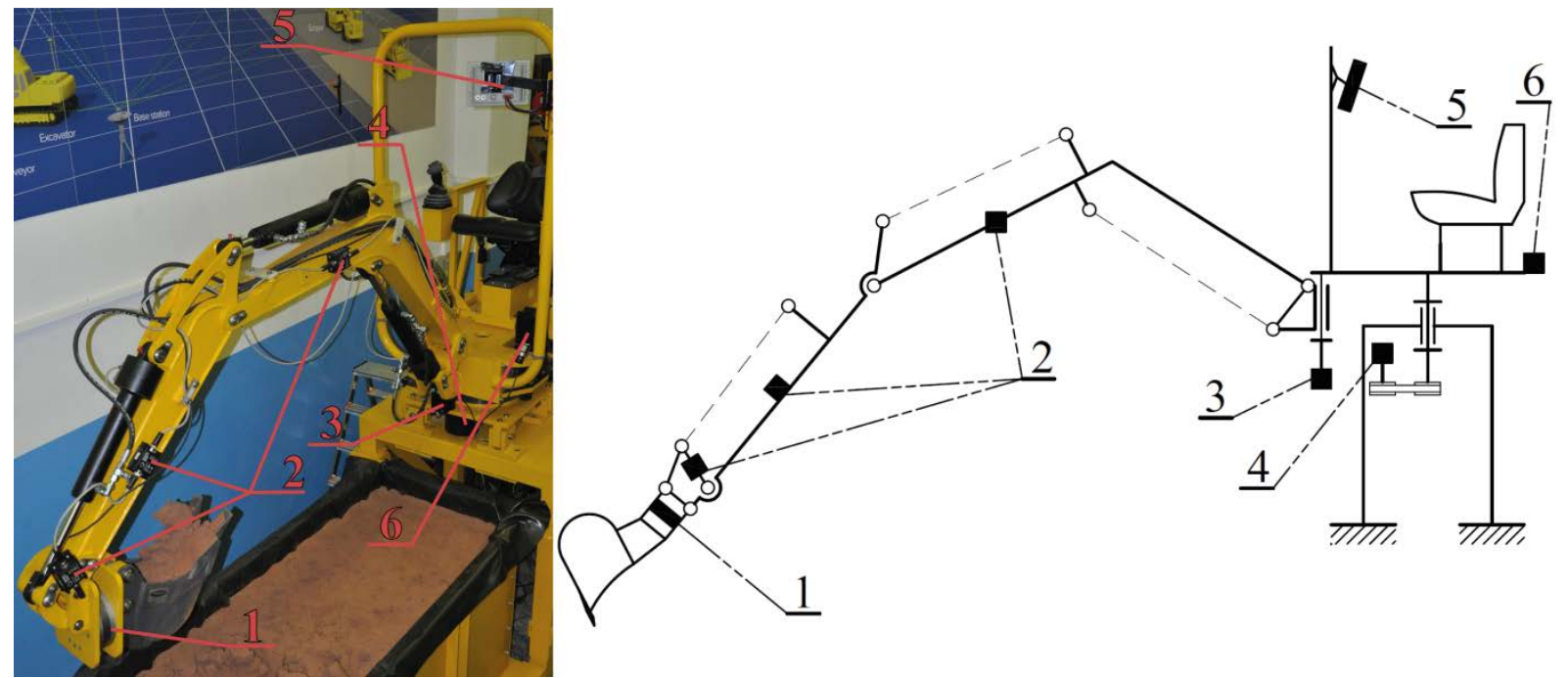

Fig. 1: Elements of a prototype system for monitoring tip over stability mounted on a test stand; 1 - sensor for measuring component loads acting on the excavator bucket; 2 - inclinometers mounted on the manipulator units; 3- optical encoder measuring the angular position of the swing bracket relative to the body; 4 - optical encoder measuring the angular position of the body relative to the chassis; 5 - microcontroller with monitor; 6 - dual axis inclinometer for measuring inclination angles of the ground plane.
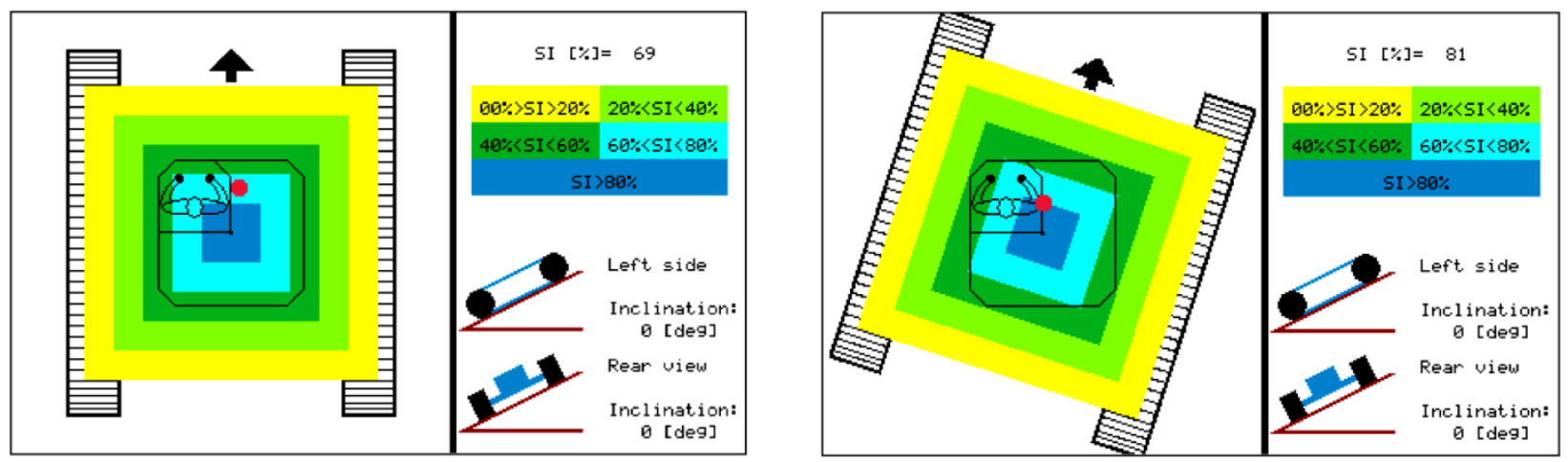

Fig. 2: Exemplary pictograms visible on the screen of a developed device during its experimental testing.

\section{References}

Dudziński, P. and Skurjat, A. R. (2012a) Experimental and simulation studies on snaking movement of wheeled articulated body steer vehicles Part I. Experimental studies. Przegląd Mechaniczny. 2012, Nr 10, pp. 31-35. (in Polish)

Dudziński, P. and Skurjat, A. R. (2012b) Experimental and simulation studies on snaking movement of wheeled articulated body steer vehicles Part II. Simulation studies. Przegląd Mechaniczny. 2012, Nr 11, pp. 29-32. (in Polish)

Dudziński, P. and Kosiara, A. (2015) Influence of tire and ground stiffness on articulated wheeled earth-moving machine’s tip-over stability. Transport Przemysłowy i Maszyny Robocze. 2015, Nr 2, pp. 39-47. (in Polish)

Dudziński, P., Kosiara, A., Czabanowski, R., Stefanow, D., Konieczny, A., Skurjat, A. R. (2016) Demonstrator of an innovative comprehensive system for assistance of the operator of bucket excavators. Journal of KONES. 2016, vol. 23, Nr 3, pp. 107-114.

Dudziński, P. and Sierzputowski, G. L. (2017) New generation test equipment for experimental identification on roll-over stability in wheeled off-road machines and vehicles. Proceedings of the 19th International \& 14th European-African Regional Conference of the International Society for Terrain-Vehicle Systems, September 2527, 2017, Budapest (in Hungary).

Kosiara, A. and Stefanow, D. (2017a) Development and validation of a system for monitoring of tip over stability of a single bucket excavator. Proceedings of the 19th International \& 14th European-African Regional Conference of the International Society for Terrain-Vehicle Systems, September 25-27, 2017, Budapest, (in Hungary).

Kosiara, A. (2017b) Evaluation of usability of different parameters in estimation of the rollover stability of a single bucket tracked excavator. Autobusy. 2017, Nr 6, pp. 810-815. (in Polish) 